\title{
The Impact of Micro-Finance on the Performance of Small-Scale Enterprises: A Comparison of Sinapi Aba Trust and Maata-N-Tudu Associations in Wa Municipality, Ghana
}

\author{
Agbenyo Fauster \\ Department of Planning and Management \\ University for Development Studies, Wa Campus, Ghana \\ fagbenyo2002@yahoo.co.uk \\ DOI: http://dx.doi.org/10.4314/gjds.v11i2.1
}

\begin{abstract}
Literature on the impact of micro-finance institutions (MFIs) on small and medium scale enterprises (SMEs) is still fraught with inconsistent results, with some concluding on positive impacts while others reporting negative impacts. This paper therefore sets out to assess the impact that the study-MFIs are making on their SMEs-client in the Wa Municipality. The withand-without approach, coupled with a quasi-longitudinal approach was employed for the study. Data were gathered from the study-MFIs' documents and questionnaire administration. Simple percentage change was used as a measure of growth of mean sales revenue. Analysis of variance (ANOVA), Spearman's correlation coefficient ( $r$ ) and coefficient of determination were also used in the analyses, with various hypotheses tests. It is concluded that the study-MFIs make positive impacts on the mean sales revenues of their client - SMEs, with great differences between those of SAT and MTA clients on the one hand and those of the control group on the other. A slight difference that exists between the two study-MFIs was accounted for by differences in their management approaches. A strong positive correlation exists between average sales revenue on one hand and micro loans, level of education and training on the other.
\end{abstract}

Keywords: Small-scale Enterprises, Micro-Financing, Micro-Credit, Sales Revenue, Impact

\section{Introduction}

Micro-financing, which was championed by the ground-breaking work of Muhammad Yunus, the father of micro finance in Bangladesh in the early 1970s (Yunus, 2007), later caught on with the rest of the developing world. One of the prime purposes of microfinancing is the provision of financial intermediation specifically in the form of micro- 
credit to small scale enterprises (SSEs), which are mainly businesses of the poor. Poverty reduction, one of the goals of micro-financing, is premised on the fact that majority of these poverty-stricken people are often identified with the small and medium scale enterprise sector. The aggregate contributions of these SSEs to economic growth and development of especially the developing economies cannot be underestimated (ChamleeWright, 2005).

MFIs generally set poverty reduction, based on microcredit, as their major goal. For example, Micro Credit Summit Campaign, an umbrella organization of major MFIs in the world, has its themes of operation and goals as: Reaching the Poorest, Empowering, Building Financially Self-sufficient Institutions, and Ensuring a Positive, Measurable Impact on the Lives of Clients and their Families (Ayesha, 2006). The success story of most of these MFIs, especially in poverty reduction and financial self-sufficiency, with some transforming into regulated non-banking financial institutions with profit motive (Xavier, 2005; White, 2005), and others becoming banking financial institutions is now serving as an indicator of profitability to analysts, policy makers, academics and development practitioners. However, with the statement: "You'll see that they are definitely poor... They repay the loans through nothing but hard work, every day" (Yunus, 2007: 48), the question can be raised as to whether the growth generated by the SSEs can be attributed to the support from the MFIs.

Following the Bangladeshi experience, which antecedent operations started in the early 1970 and later transformed into the Gremeen Bank in 1985, are several MFIs in various regions of the world, which according to Flohlich et al. (1994) came in various shades. Afrane (2006) identifies five major categories of MFIs in Ghana. These include financial NGOs, Savings and Loans Companies, Rural Banks, Credit Unions and Rotating Savings Credit Institutions (Susu Groups). The World Bank development indicators show that in 2004, Ghana's formal and semi-formal MFI sector reached approximately 1.5 million clients, with less than 30 percent receiving loans. As of December 2010, globally, 3,652 MFIs reported reaching 205,314,502 clients, of whom 137,547,441, constituting 67 percent, were among the poorest when they took their first loan (Maes \& Reed, 2012).

Literature, however, does not converge on the impact MFIs make on their SME clients. It shows a lot of mixed results. Some studies have concluded on negative results while others have pointed out positive ones while still others settled on both positive and negative results with varying proportions (Roodman, 2012; Armendariz \& Morduch, 2010; Bateman, 2010; Ditcher \& Harper, 2010; Dunn \& Arbuckle, 2001; ). This paper seeks to determine the impact MFIs are making on their SSEs clients; to establish the relationship that exists between micro credit and sales revenue; and to undertake a comparative analysis of the SSEs supported by the respective study-MFIs. The discussion focuses on non-governmental organization (NGO) micro credit schemes (Flohlich et al. 1994; Afrane, 2006), with the time frame of analysis spanning a three-year period; 2009/2010-2011/2012 loan cycles. This period is long enough to measure impacts as well as show trends. The rest 
of the paper is devoted to the study area, theoretical framework, methodology, results and discussions, and conclusion.

\section{Study Area}

The Wa Township serves both as the administrative capital of the Wa Municipality as well as the capital of the Upper West Region of Ghana. It is located in the north-western part of Ghana. The Municipality has a total land area of approximately $234.74 \mathrm{~km}^{2}$, about $6.4 \%$ of the area of Upper West Region (Aduah \& Aabeyir, 2012; 658). It has a population of 107,214 persons, a total male population of 52,996 and a total female population of 54,218 as at 2010 (GSS, 2012). The annual growth rate in the Municipality's population was $4.0 \%, 3.7 \%$, and $3.8 \%$ respectively between 1960 and 1970, 1970 and 1984, and 1984 and 2000 (GSS, 2005), with the 2000 and 2010 growth rate standing at 1.9\% (GSS, 2012). This relatively low 2000-2010 inter censal growth rate is explained by the fact that in 2010, prior to the population and housing census, the then Wa Municipality was re-demarcated into Wa Municipality, Wa East and Wa West Districts. The Upper West Region in general, of which the Wa Municipality is a part has been rated as the poorest region in Ghana (GSS, 2008). The Wa Municipality is often acclaimed as a private-sector business enclave in the Upper West Region with a preponderance of SSEs.

\section{Theoretical Framework}

\section{The Micro-Finance Debate}

The literature on micro-finance reveals two schools of thought - the social mission school and the commercialization school. Social mission advocates are emphatic on the disincentive on the part of commercial banks to serve the poor. Reasons assigned include the high cost associated with the high risk posed by the poverty and unprotected property rights of these clients (Wardle, 2005). They put MFIs which charge 'high interest' on par with loan sharks and moneylenders, and argue for non-profit organizations, with philanthropic donations and commercial finance as their sources of capitalization. The social mission advocates are committed to poverty reduction, as the most desired option thereby often stepping in to play this role of intermediation for the poor. The social missionaries therefore call for subsidization of micro-finance institutions (Schreiner, 2003) as this will translate into pareto-efficient ${ }^{1}$ outcomes in the form of social gains (Khandker, 1998). Zvi (2002) for example, went to the extreme and calls for interest on loans to be below those of commercial banks while interest on savings of beneficiaries should be higher than the banks'.

1 Pettinger (2014) defines Pareto Efficiency as "when it is impossible to make one party better off without making someone worse off. It is an economic state where resources are distributed in the most efficient way". See Pettinger, T. R. (2014). Pareto Efficiency. Available: http://www. economicshelp.org/blog/glossary/pareto-efficiency/. Accessed: $14^{\text {th }}$ August, 2014. 
Commercialization advocates, on the other hand, are of the view that there are perverse incentives associated with continued reliance on donor support (Christen, 2001b as cited by Chamblee-Wright, 2005; Simpson-Herbert \& Wood, 1998 and CGAP, 2003). They therefore refute the pareto-efficiency position, arguing that it is premised on static view of resource allocation. For them, commercialization is rather the means by which the best interest of borrowers, lenders and private investors can be served (Chamblee-Wright, 2005: 7). One of the objectives of the financial sector reforms in the last two decades of the twentieth century, in Ghana, was to introduce competition on to the financial market and induce efficient financial practices which will result in reduction in interest rates. These falling interest rates were to result, in part, from leveling of demand for credit (Aryeetey, 1996), which can only be born out of gains made from profit-yielding economic activities undertaken by micro entrepreneurs. Helms and Xavier (2004) justify higher cost on micro loans (market driven interest rates). Using greater delivery costs of tiny transactions, they concluded that even if MFIs stimulate innovations which will improve their productivity further to reduce administrative costs thus improving interest rates, micro lending will still cost more than conventional lending.

The two schools have a common thread - to serve the best interest of the poor, by delivering financial intermediation services to them. The difference in approach, however, has opened both sides to certain serious flaws. The 'social missionaries' have taken for granted the possibility of donor fatigue leading to unexpected cuts in funding. The 'commercialisation advocates', are also oblivious of who a poverty-stricken micro-credit client is. Even though the dynamic view of resource allocation they espouse hold a lot of prospects, to bring the abject poor out of the doldrums and launch them onto the path of prosperity to take active part in competitive business, they cannot start with paying commercial prices on capital. What is certain in these schools of thought is the fact that they both have their strengths and weaknesses; a blend between the two views can therefore be useful. The concern here is, what impact has been made so far by these MFIs whether commercialisation advocates, social missionaries or a blend of the two?

\section{Financial Arrangements in Support of SSEs in Ghana}

In Ghana, conscious efforts at financing SMEs can be traced to as early as the colonial era in 1934, with the establishment of the Bureau of African Industries at Takoradi (Gold Coast Examiner, 1938 cited in Boappeah and Poppe, 1992). Since then, various governments have attempted to finance SMEs, using various strategies.

In 1970, the Bank of Ghana established a credit guarantee scheme with a value of US\$28 million from the International Development Association (IDA) of the World Bank to establish a Fund for Small and Medium Enterprises Development (FUSMED). This fund was administered by some financial institutions for the support of SMEs in all sectors of the economy, except primary agriculture, trading and real estate activities. Under the Programme of Action to Mitigate the Social Cost of Adjustment (PAMSCAD), a revolving credit amounting to US\$2 million was established for SSEs (Helmsing \& Kolstee, 1993). The 
establishment of the National Board for Small Scale Industries (NBSSI) by the NBSSI Act (1981) Act 434 under the Ministry of Trade and Industry provides both an institutional and financial support to SSE. The Board is said to be operating the following three small financial schemes to assist the SSEs in keeping petty cash since its inception: Programme of action to mitigate the social cost of adjustment (PAMSCAD), NBSSI Revolving Fund Scheme and Micro and Small Loans Scheme (MASLOC). The Revolving Fund Scheme and MASLOC are still functional while the PAMSCAD has wound up. The implementation of the financial sector reform that got underway since the late 1980s (Hutchful, 2002), which itself has gone through several transformations since, has created a space for the private financial sector to participate in the business sector of the Ghanaian economy.

\section{Performance of Micro-Finance Institutions- Client Small and Medium Enterprises}

Available literature has shown mixed evidence of the impact of MFIs on the performance indicators of SMEs. Studies have established that there exists a positive relationship between the operations of micro-finance institutions and the revenues of their microenterprise clients (Mosley, 1996; Sebstad \& Walsh, 1991 and Montgomery et al., 1996, as cited in Dunn \& Arbuckle, 2001). Montgomery et al. (1996), Nelson and Bolnick (1986), and Diagne and Zeller (2001) have also concluded that micro-credit has not impacted positively the incomes of their clients. In the area of fixed assets, Aryeetey et al. (1994), Montgomery et al. (1996), Nelson \& Bolnick (1986), Sebstad \& Walsh (1991) have established that microcredit has exerted positive effect on small enterprises, while others like Barnes (2001) and Aryeetey et al. (1996), Mosley (1996), Nelson \& Bolnick (1986), Chen \& Snodgrass (2001) found positive incidence of micro-credit on small enterprises, with Barnes (2001) and Montgomery et al. (1996) indicating that there is little or no effect at all on micro and small enterprises. Using an analysis of covariance (ANCOVA) between a treatment and a control group, Dunn \& Arbuckle (2001) established that micro loans exert significantly positive effect on micro and small enterprise revenues and employment.

\section{Methodology}

\section{Research Design for the Study}

The study is an impact study, which applied a quasi-longitudinal approach to multiple case studies for comparative analyses. The quasi-longitudinal approach spans a threeyear-period (Nixson and Cook, 2005: 348-350) and was mixed with the with-and-without approach (Littlefield et al., 2003; and Dunn \& Arbuckle, 2001) was used involving business enterprises supported by MFIs and a control group (which are micro enterprises with similar characteristics but without access to micro-finance). This is to have a fair idea of the situation of those enterprises outside MFI beneficiaries and also to establish the impact made on the supported SMEs by their MFI supporters. 


\section{Sampling and Data Collection}

The sample population comprises all micro enterprises which had access to credit from SAT and MTA between 2009 and 2012 in the Wa Municipality. The sample size was determined, using a formula by Spiegel (1961) in which $n_{i}=$ independent sample sizes of the study, $\mathrm{N}_{1}=\mathrm{N}_{1}+\mathrm{N}_{2}+\mathrm{N}_{3}$ (population sizes) for the three different groups and e = error margin allowed (at 10\%). In all, a total sample of 120 small enterprises was covered comprising 46 (38 percent) and 40 (33 percent) of the 84 and 67 clients of the SAT and MTA respectively. The rest 34 (29 percent) of the sample captured, represent the control group. MTA and SAT were selected purposively out of three non-governmental-organizations (NGO)-based MFIs, identified to be providing micro credit in the Wa Municipality. The third MFI, Centre for the Development of People (CEDEP), was automatically dropped from the sampling because the NGO that was behind its micro credit scheme folded up before the start of the data collection. To select the micro-enterprise clients of the two MFIs, simple random sampling (SRS) technique was used. The serial numbers of these SMEs (which also coincide with micro - credit clients), on the micro credit lists (which served as the sample frame) were used to identify them. Since no sample frame could be established for the control group, a purposive convenience sampling method was adopted. Direct interviews (one-on-one and key informant), focus group discussions and questionnaire administration were used to complement data gathered from the records. Data were collected from records of the MFIs and micro enterprises supported by them. Simple percentage change was used as a measure of growth of mean sales revenue. Analysis of variance (ANOVA), Spearman's correlation coefficient $(r)$ and coefficient of determination were also used in the analyses, with various hypotheses tests.

\section{Hypotheses}

The null hypothesis (Ho) is that micro-financing has no impact on the performance of micro enterprises they support. The alternative hypothesis $\left(\mathrm{H}_{1}\right)$ is that micro-financing impacts positively on the performance of micro enterprises. In specific terms the hypotheses are expressed in relation to the relationship between sales revenues and the micro loans taken by the SSEs and analysis of variance between the means of the sales revenues of the three samples thus:

Ho: There is no significant correlation between loans taken and sale revenues of micro enterprises. $\boldsymbol{H}_{\mathbf{i}}$ : There exists a significant positive correlation between micro loans contracted and sales revenues of micro enterprises.

\section{Differences amongst the Three Sample Means}

Ho: There is no significant difference among the means of the three samples used in the study. $\boldsymbol{H}_{\mathbf{1}}$ : There is a significant difference between at least two of the means of the samples used in the study. This can be expressed statistically as: Ho: 
$\ddot{\mathbf{x}}_{\text {sat }} \ddot{\mathbf{x}}_{\text {mta }}=\ddot{\mathbf{x}}_{\mathbf{c g}}, \mathrm{H} 1 \ddot{\mathbf{x}}_{\text {sat }} \neq \ddot{\mathbf{x}}_{\text {mta }} \neq \ddot{\mathbf{x}}_{\mathbf{c g}}$, Where $\ddot{\mathbf{x}}_{\text {sat }}, \ddot{\mathbf{x}}_{\text {mta }}$ and $\ddot{\mathbf{x}}_{\text {cg }}$ are means of SAT, MTA and control groups respectively.

\section{Assumptions Underlying the Hypotheses}

i) Without the micro credits, clients were already in business and generating sales revenue; and ii) The addition of micro loans would result in increased sales revenue and implies that the number of loan cycles taken determines the ability to generate sales revenue.

\section{Results and Discussion}

\section{SAT and MTA Microcredit Administration}

The approaches adopted are tools intended for effective risk management. These approaches can be grouped into three main areas related to security approach, savings and loans approach and loans delivery and mechanism for loan repayment.

In the area of security, the solidarity group approach is used. This serves as a social control mechanism, which both appeals to and coerces the individual members to conform to laid-down group principles, rules and regulations. The solidarity groups are said to bring peer pressure on individual members within the group. Solidarity is seen at work only when an individual genuinely defaults (as in the case of bankruptcy or death and the relatives cannot pay); the group contributes to make do the payment for continued access to the loan from the institution. Recalcitrant ones, however, are sanctioned and sometimes expelled from the group. There is, however, a slight difference between the two MFIs in terms of groups used in their operations. SAT groups have core leadership called Credit Committee (CC). This is put together from the leadership of smaller groups which form a larger one. The $\mathrm{CC}$ is responsible for the day-to-day running of the groups and determination of how much loan an individual should take. They organize meetings, set the agenda and deal with issues relating to dues and loans repayment. They also engage in conflict resolution and management, sanctioning as well as rewarding subjects and are responsible for the representation of the group at any external fora. MTA groups on the other hand are smaller independent ones, whose formation is not supposed to be influenced by any external agent. On the groups' application for membership, MTA then steps in with their training and animation, toward the development of their leadership, formulation of objectives, rules, regulations and constitutions (which vary from group to group).

Next is the savings and loans approach. This approach serves as bait to clients, who will not want to lose their savings and therefore will eschew defaulting tendencies. At the same time, in case of default, the MFI is assured of a percentage of the amount due it. It also reduces the burden on group members who will contribute to pay in order to 
continue enjoying the services. The savings-to-loan rates are at least 10 percent for SAT and 17 percent for MTA. These are seen as security to the operating MFIs. The strategy of savings and loans is useful in awakening the spirit of savings which is useful not only for the small businesses in question but also for the macro economy as savings is a critical indicator for economic growth of the nation as a whole. Another reason for saving under MTA includes continued access to funds by clients to further their operations in the case of donor fatigue leading to dwindling of funds. It is also to serves as collateral for clients to access credit from MTA now and the commercial banks in future. Finally, it is to contribute to the seed capital for the Women's Bank to be established in future.

The last approach is the loan delivery and collection approach. While SAT delivers loans to clients directly through its field staff (Loan Officers), MTA does that through Agricultural Development Bank. The SAT approach, though implies higher operational cost for the organization, ensures safety of the loans and also relieves the clients of the burden of cost of transport to access its services. By organizational policy, both SAT and MTA collect installments of loan repayments through their loan officers. Though on the surface this may imply high operational cost for the organizations, on the aggregate it is more cost-effective, as evidence shows that the loan officers in totality incur less cost in both disbursement and collection of loans by reaching out to the clients than when clients have to pay individually to access loans from a central place.

\section{Comparative Analysis of Growth in Average Sales Revenues of the Samples}

Average sales revenues for SAT and MTA clients have more than doubled (that is $69.0 \%$ and 68.30 \% respectively), between 2009/2010 and 2010/2011 (see Mosley, 1996 cited in Dunn \& Arbuckle, 2001) while that of those micro enterprises without access to financial support increased only by $34.10 \%$ within the three-year period as can be computed from table 1 . By the principles of the with-and-without approach to the assessment of the results of strategies of external agents, any deviations in the performance of their clients and a control group can, to a great extent, be attributed to the external agent's strategies.

Table 1: Growth in average sales revenue of the three samples

\begin{tabular}{|l|l|l|l|l|l|}
\hline \multirow{2}{*}{$\begin{array}{l}\text { Financial } \\
\text { Institution }\end{array}$} & \multicolumn{4}{|l|}{ Mean Sales Revenue } \\
\cline { 2 - 6 } & $2009 / 2010$ & $2010 / 2011$ & $\begin{array}{l}\text { (\% Annual } \\
\text { Rise) }\end{array}$ & $2011 / 2012$ & $\begin{array}{l}\text { (\% Annual } \\
\text { Rise) }\end{array}$ \\
\hline MTA & $\$ 188.82$ & $\$ 317.81$ & $68.3^{*}$ & $\$ 424.06$ & $33.4^{*}$ \\
\hline SAT & $\$ 146.16$ & $\$ 246.94$ & $69^{*}$ & $\$ 362.15$ & $46.7^{*}$ \\
\hline Control Group & $\$ 164.10$ & $\$ 198.15$ & $20.7^{*}$ & $\$ 224.68$ & $13.4^{*}$ \\
\hline Total & $\$ 165.46$ & $\$ 25.76$ & & $\$ 343.84$ & \\
\hline
\end{tabular}

Source: Computed from Field Survey Data, June, 2012. ${ }^{*}=$ Growth Rates in Sales Revenues 
The control group has achieved growth, though lower and without any financial support from MFIs. This was alluded to by Aryeetey et al. (2001) that SMEs experience growth even without support from MFIs.

\section{Analysis of Variance (ANOVA) for the Three Samples and the F-Test}

From table 2, $\mathrm{F}_{\mathrm{obs}}=13.417>\mathrm{F}_{\text {crit }}=6.36$ at 2 degrees of freedom. The null hypothesis is thus rejected at 0.01 level and conclusion drawn that there exists a significant difference between at least two of the means. Since the ANOVA test is non-directional, this result does not tell which means differ. To determine how the sample means differ from each other, a multiple comparative analysis among the independent sample means is used as shown in Table 2. It shows that a difference exists between the means of SAT and MTA on one hand and that of the control group on the other at 0.01 level; while that which exists between the means of SAT and MTA is as low as 0.1 level of confidence. These findings go to confirm those of Dunn and Arbuckle, 2001 and Nixson, and Cook, 2005, who found out that differences existed between the means of the treatment and control groups of their study.

Table 2: (a) Sales revenue ( $\$$ )

\begin{tabular}{|l|l|l|l|l|l|}
\hline Categorization & Sum of Squares & df & Mean Square & F & Sig. \\
\hline Between Group & $6,951,464,069.538$ & 2 & $3,475,732,034.769^{* *}$ & 13.417 & .000 \\
\hline Within Group & $3,010,287,103.469$ & 117 & $259,062,282.936$ & & \\
\hline Total & $372,617,512,042.573$ & 119 & & & \\
\hline
\end{tabular}

Source: Computed from field data, June, 2012. ${ }^{* *}$ The mean difference is significant at the 0.01 level.

\section{Post Hoc Tests: Multiple Comparisons}

It can thus be concluded that SAT and MTA have really made an impact on the sales revenue of their clients, while at the same time slight differences in organizational policy have resulted in slight differences in sales revenues of the two MFIs (see Table 3 ).

Table 3: Least Significant Difference LSD: Dependent Variable, Sales Revenue (\$)

\begin{tabular}{|l|l|l|l|l|}
\hline (I) Sample Groups & (J) Sample Groups & Mean Difference (I-J) & Std. Error & Sig. \\
\hline MTA & SAT & $61.91^{*}$ & 62.28 & .091 \\
\hline MTA & Control Group & $90.68^{* * *}$ & 39.14 & .000 \\
\hline SAT & Control Group & $137.48^{* * *}$ & 37.95 & .000 \\
\hline
\end{tabular}

${ }^{* * *}$ The mean difference is significant at the 0.01 level. ${ }^{*}$ The mean difference is significant at the 0.1 level 


\section{Conclusion}

It is evident that there exists positive relationship between financial intermediation services of MFIs and the SSEs they support. Growth in sales revenues of the two MFIsupported SSEs far outstrips those of the control group, which further buttresses the fact that MFIs are impacting positively on the SSEs they support. The difference under the ANOVA in sales revenue of SAT and MTA is attributed to differences in institutional strategy. It must be emphasized that this analysis focuses only on the growth generation capacity (particularly in terms of income) of the MFI-SSE sector. This paper has not touched on the distributive aspect of the generated growth. This, certainly, is a subject of discussion for another research. The income generating component of the drive to poverty reduction should, at least in part, be assigned to credible MFIs. This can be done in two ways; firstly, through policy guidelines and legislative provisions, which can unify and aid in monitoring the activities of the MFIs. Secondly, government can make some funds available and accessible from the Millennium Challenge Accounts (MCA) to pro-poor MFIs. This is to put into effect the partnership among the three sectors of developing a society (public-private-civil society sectors in partnership). This is to enable the economy take advantage of the specialized methodology evolved by the MFIs in reaching out to the poor.

\section{References}

Abena, D.0. (2004). A Note on public expenditure and poverty reduction. In Aryeetey, E. \& Kambur, R.S. Macroeconomic stability and, growth and poverty reduction in Ghana. (Ed.). Accra: ISSER, pp. 214-236.

Aduah, M.S. \& Aabeyir, R. (2012). Land cover dynamics in Wa Municipality, Upper West Region of Ghana. In Research Journal of Environmental and Earth Sciences 4(6):658-664, 2012.

Afrane, S. (2006). Micro financing and poverty reduction, Daily Graphic. p.7.

Allen, R. E. (1990). The Concise Oxford Dictionary of current English (ed). Oxford, UK: Clarendon Press.

Armenadrize, B. and Moduch, J. (2010). The economics of microfinance ( $2^{\text {nd }}$ ed.). United State of America: Massachusetts Institute of Technology.

Asiama, J.P. (2007). Micro-finance in Ghana: An Overview. Accra, Ghana: EWI. Available at: http://www.economicswebinstitute.org/essays/microfinance ghana.htm. Accessed: 16th December, 2013.

Aryeetey, E. (1996). Credit for enterprise development. In Aryeetey, E. (Ed.), Small enterprise credit in West Africa. Accra: British Council/ISSER Publication. Pp. 226245 . 
Aryeetey, E. (1996). The formal financial sector in Ghana after the reforms. Working Paper 86, London.

Aryeetey E., Baah-Nuakoh A., Duggleby T., Hettige H. \& Steel W.F. (1994). Supply and demand for finance of small scale enterprises in Ghana. World Bank Discussion Paper No. 251.

Ayesha, G. (2005). "Micro credit poised to reach 100 million families". Inter Press Service [IPS] News Agency. Retrieved 27 $7^{\text {th }}$ August, 2014 from http://www.ipsnews.net/2005/12/ development-microcredit-poised-to-reach-10o-million-families/.

Barnes, C. (2001). Microfinance program clients and impact: An assessment of Zambuko Trust, Zimbabwe. AIMS Paper. Washington, DC: Management Systems International.

Bateman, M. (2010). Why doesn't microfinance work? The destructive rise of local neoliberalism. London: Zed Books Ltd.

Boapeah, S.N. and Poppe, M. (1992). Strengthening spatial circuits of rural small industries for district development: A case study of Dangme West District, Ghana. Dortmund: Spring Research Series.

Buzzard, S. and Edgcomb, E. (1992). Monitoring and evaluating small business projects: A step-by-step guide for private development organization (Ed.),. New York, U.S.A.: United Nations Plaza.

Carmen, C. (2002). Micro credit interest rates, Occasional Papers No. 1.

Chamley-Wright, E. (2005). "Fostering sustainable complexity in the micro finance industry: Which way forward”? Economic affairs. Oxford, U.K. Blackwell Publishing, Vol. 25 No. 2 pp. 5-12.

Chen, M. and Snodgrass, D. (2001). Managing Resources, Activities, and Risk in Urban India: The Impact of SEWA Bank. Washington DC. USAID.

Daley-Harris S. (2005). State of the Micro Credit Summit Campaign 2005 report: Available at; www.microcreditsummit.org. Accessed: 14th January, 2014.

De Soto, H. (2001). The Mystery of capital, London: Black Swan Publications.

Diagne, A. and Zeller, M. (2001). Access to credit and its impact on welfare in Malawi. Washington DC: International Food Policy Research Institute.

Ditcher, T. and Harper, M. (2010). What's wrong with microfinance? Warwickshire: Practical Action Publishing, pp. 225-240.

Dunn, E. and Arbuckle, G. J. (2001). Micro credit and micro enterprise performance: Impact evidence from Peru. In Small enterprise development: An International Journal 
of micro finance and business development, YIDG Publishing, London. Vol. 12, pp. 2232.

Frohlich et al. (1994). Manual for small industrial businesses: Project design and appraisal; Vienna, UNIDO Publication.

Ghana Statistical Service (2008). Ghana living standards survey Report of the fifth round (GLSS 5). Accra, Ghana Statistical Service (GSS).

Ghana Statistical Service (2012). 2010 Population and housing census: Summary report of the final results. Accra: Ghana Statistical Service (GSS).

Ghana Statistical Service (2005). 2000 Population and housing census, Upper West regional analysis. Accra: Ghana Statistical Service (GSS).

Graeme, L. (2005). Industry. Microsoft Encarta Encyclopedia Standard 2005.

Helms, B. and Xavier, R. (2004). Interest rate ceilings and microfinance: The story so far. CGAP. Available at: www.cgap.org. Accessed: $20^{\text {th }}$ February 2014.

Helmsing, A. H. J. and T, Kolstee (1993). Small enterprises in a changing policy environment in Africa: Raising issues and attempting answers in small enterprises and changing policies. London: IT Publications.

Hutchful, E. (2002). Ghana's adjustment experience: The Paradox of reform. United Nations Research Institute for Social Development in association with WOELI Publishing Services.

Khandker, S. (1998). Fighting Poverty with Micro Credit: Experience in Bangladesh, New York: Oxford University Press.

Littlefield, E.; Morduch, J. and Hashemi, s. (2003). Is microfinance an effective strategy to reach the millennium development goals? In Focus note. Washington DC: CGAP. Available at: www.cgap.org\%2Fsites\%2Fdefault\%2Ffiles\%2FCGAP-Focus-Note-IsMicrofinance-an-Effective-Strategy... Accessed: $20^{\text {th }}$ February 2014.

Maes, J. P. and Reed, L. R. (2012). State of the Microcredit Summit Campaign report 2012. Washington, D.C. Microcredit Summit Campaign [MCS].

Montgomery, R., Davies, R., Saxena, N. C. and Ashley, S. (1996). Guidance Materials for Improved Project Monitoring and Impact Review Systems in India, Swansea: Centre for Development Studies, University College Swansea.

Mosley, Paul (1997). The use of control groups in impact assessment for microfinance. Washington DC. Consultative Group to Assist the Poorest (CGAP). 
National Board for Small Scale Industries (2014). Financial services. Available at: http:// www.nbssi.org/FinancialServices.aspx. Accessed: 15th January, 2014.

Nelson, E. R. and Bolnick, B. R. (1986). Survey methods for assessing small credit programs. evaluating the economic impact of KIK/KMKP Credits. Jakarta.

Nixon, F. and Cook, P. (2005). Small and medium enterprises in developing economies. In Green, C. J. et al. (Eds.). Finance and Development: Surveys of theory, evidence and policy. U. K.: Edward Elgar Publishing Limited, pp. 381-404

Roderick, D. (2000). Growth vs. poverty reduction: A Hollow debate. In Finance and development: International Monetary Fund: Washington, DC 20431, USA.

Roodman, D. (2012). Due diligence: An impertinent inquiry into microfinance. Washington, D.C.: Center for Global Development.

Sebstad, J. and Walsh, M (1991). Microenterprise credit and its effects in Kenya: An Exploratory study. Report prepared for USAID AFR/MDI and S\&T/WID. Washington, D.C.: Coopers and Lybrand.

Simpson-Herbert, M. and Wood, S. (Eds.) (1998). Sanitation promotion. Geneva: World Health Organisation.

Spiegel, M.R. (1961). Theories and problems of statistics. New York: Schaum Publishing Company/McGraw Hill.

Steel, W. F. (1996). Demand for finance by SMEs in West Africa: How can the constraints be broken? In Aryeetey, E. (Ed.). Small enterprise credit in West Africa. Accra: British Council/ISSER Publication.

White, V. (2005). Workshop Session: Transformation of micro-finance operations from NGO to a Regulated MFI. Micro Credit Summit E-News, Volume 3, Issue 1. Available at: www. microcreditsummit.org/. Accessed: 2oth February, 2014.

Xavier, R. (2005). Workshop Session: Transformation of micro-finance operations from NGO to a regulated MFI. Micro Credit Summit, E-News (Volume 3, Issue 1: April). Available at: www.microcreditsummit.org/. Accessed: $20^{\text {th }}$ February, 2014.

Yunus, M. (2007). Creating a world without poverty: Social business and the future of capitalism. New York; PublicAffairs ${ }^{\mathrm{TM}}$.

Zvi, G. (2002). Micro-finance visionary showcase: A new concept. Co-op Dialogue - An ICA ROAP Journal Vol. 12, No, 1\&2. pp. 186 - 207. 